Aquaculture

October 2016, Volume 463, Pages 79-88

http://dx.doi.org/10.1016/i.aquaculture.2016.05.015

http://archimer.ifremer.fr/doc/00334/44518/

(c) 2016 Published by Elsevier B.V. All rights reserved.

\title{
Domestication compromises athleticism and respiratory plasticity in response to aerobic exercise training in Atlantic salmon (Salmo salar)
}

\author{
Zhang Yangfan ${ }^{1,}{ }^{*}$, Timmerhaus Gerrit ${ }^{2}$, Anttila Katja ${ }^{3}$, Mauduit Florian ${ }^{4,5}$, Jørgensen Sven Martin ${ }^{2}$, \\ Kristensen Torstein ${ }^{6}$, Claireaux Guy ${ }^{4,5}$, Takle Harald ${ }^{2,7}$, Farrell Anthony P. ${ }^{1}$
}

${ }^{1}$ Department of Zoology \& Faculty of Land and Food System, University of British Columbia, Vancouver, British Columbia, Canada

${ }^{2}$ Nofima AS, Ås, Norway

${ }^{3}$ Department of Biology, University of Turku, 20014 Turku, Finland

${ }^{4}$ Laboratoire des Sciences de l'Environnement Marin (LEMAR), Université de Bretagne Occidentale,

France

${ }^{5}$ Unité de Physiologie Fonctionnelle des Organismes Marins, Ifremer, Plouzané, France

${ }^{6}$ Faculty of Biosciences and Aquaculture, Nord University, Bodø, Norway

${ }^{7}$ Marine Harvest ASA, Norway

* Corresponding author : Yangfan Zhang, email address : yangfan@zoology.ubc.ca

\begin{abstract}
:
Commercially selective breeding of Atlantic salmon (Salmo salar) primarily for rapid growth may compromise cardiorespiratory robustness and its related phenotypes. Therefore, a suite of respiratory indices was used to evaluate aerobic capacity and hypoxia tolerance to test the hypothesis that exercise training can improve the athletic robustness in both domesticated and wild strains of Atlantic salmon, but with the domesticated strain having a less cardiorespiratory plasticity and a lower athletic robustness than the wild strain. We also tested a second hypothesis that a constant acceleration screening protocol should segregate fish according to athletic robustness based on their swimming ability. These hypotheses were tested with parr from Bolaks (domesticated) and Lærdal (wild) strains of Atlantic salmon that were reared under identical hatchery conditions. After screening into either inferior (bottom 20\%) or superior (top 20\%) swimmers, the four groups of fish (two strains and two swimming performance levels) either were given an 18-day exercise-training regime (an incremental water current of 2.0-2.8 fork lengths $\left.\mathrm{s}^{-1}\right)$, or were maintained at the control water current $\left(0.5\right.$ fork length $\left.\mathrm{s}^{-1}\right)$ for 18 days. Subsequently, fish were sampled for metabolic enzyme analysis in red and white swimming muscles (citrate synthase, CS, and lactate dehydrogenase, $\mathrm{LDH} ; \mathrm{n}=15$ from each group) and their individual respiratory capacities were comprehensively assessed by measuring the standard metabolic rate (SMR), maximum rate of oxygen uptake $\left(\dot{M O}_{2 \max }\right)$, absolute aerobic scope (AAS), factorial aerobic scope (FAS), excess post-exercise oxygen consumption (EPOC), critical oxygen level $\left(\mathrm{O}_{2 \text { crit }}\right)$ and incipient lethal oxygen saturation (ILOS). Contrary to our expectations, the inferior and superior swimmers were indistinguishable in either strain and these data were pooled. While exercise training produced several tangible benefits for the wild fish, it produced very few for the domesticated fish. For example, the wild strain, but not the domesticated strain, had a significantly higher $\dot{M} \mathrm{O}_{2 \max }$, AAS and
\end{abstract}


EPOC as a result of training. Also, CS activity in red muscle increased after training to a larger extent in the wild strain than in the domesticated strain. When compared with the wild strain, the domesticated strain had a significantly lower $\dot{M O}_{2 \max }$, AAS, FAS and CS activity in white muscle. Thus, the domesticated strain appeared to be athletically less robust than the wild strain. These results imply that approximately ten generations of selective breeding for rapid growth in commercial aquaculture have reduced the overall athletic robustness of domesticated salmon as compared to their wild conspecifics, and given the success in improving athletic robustness of the wild strain, it still remains to be seen whether an exercise training protocol can be developed that will provide benefits to the salmon aquaculture industry.

\section{Statement of relevance}

This manuscript fits perfectly with the scope of aquaculture. We address the possibility that the Norwegian Atlantic salmon (Salmo salar) breeding program that extensively focuses on commercial benefits traits may be compromising the cardiorespiratory system, which may contribute to the mortality of smolts after seawater transfer. We hypothesized that a combination of exercise-screening and exercise-training protocols could select for superior cardiorespiratory performance. This hypothesis was tested by comparing domesticated and wild Norwegian Atlantic salmon strains, and using comprehensive measurements of athletic and hypoxia performance in individual fish.

We believe this paper will be of specific interest to aquaculture professionals who are seeking the enhanced husbandry approaches for achieving higher survival rate over seawater transfer as well as general physiologists. To our knowledge our study is the first to comprehensively illustrate athleticism of domesticated Atlantic salmon from biochemical and cardiorespiratory system levels. Furthermore, we believe this is the first study to show the promising results of enhancing cardiorespiratory system of domesticated Atlantic salmon strain in a hatchery setting.

We used a suite of respiratory indices to evaluate athletic robustness and hypoxia performance in individual fish. We discovered that a domesticated strain of Atlantic salmon demonstrated a reduced athleticism and less plasticity in response to a short exercise-training regime compared with a wild strain of Atlantic salmon. We conclude that commercial aquaculture practices may trade off the robustness of the cardiorespiratory system, but not to an extent of completely losing the potential of benefiting from exercise training.

\section{Highlights}

A suite of respiratory indices was used to evaluate athletic robustness and hypoxia tolerance of Atlantic salmon. A domesticated strain had a reduced athleticism and less plasticity in response to a short exercise-training regime compared with a wild strain. We conclude that while commercial aquaculture practices appear to trade off the robustness of the cardiorespiratory system, the potential of benefiting from exercise training is not completely lost.

Keywords : Athletic robustness, Atlantic salmon, domestication, exercise training, hypoxia tolerance, respiratory performance 


\section{Introduction}

Freshwater production of Atlantic salmon smolts in commercial aquaculture is characterized by high intensity production (Kristensen et al., 2009; 2012a) and several handling procedures, such as grading, vaccination and transport, which are physiologically challenging. A particularly critical production procedure is the transfer of smolts to seawater transfer because it is associated with significant mortality (Maxime et al.,1986; Maxime et al.,1990; Jørgensen and Jobling, 1994, Iversen et al., 2005). In Norway alone, a 15-20\% mortality rate still accompanies salmon growout in sea at the first 90-day, which amounts to 40-50 million fish annually (Kristensen et al., 2012a). Both the osmo-respiratory compromise (McCormick and Saunders, 1987; Randall and Brauner, 1991; Gallaugher et al., 2001; Sardella and Brauner, 2007) and lower cardiorespiratory fitness (Castro et al., 2011) have been implicated as underlying mechanisms for this mortality, with secondary disease outbreaks as a diagnosed cause of death (Aunsmo et al., 2008).

A fish's activities are ultimately governed by the capacity of its cardiorespiratory system to supply oxygen to working tissues, making this system a determining factor of a fish's ability to face environmental contingencies, whether of natural or anthropogenic origin. It therefore seems reasonable to assume that within a population, those individuals with the greatest cardiorespiratory capacity will be less likely to suffer energy budgeting conflicts as they have a greater capacity to multitask (Neill et al., 1994). In farmed Atlantic salmon, this advantage could translate into improved survival during seawater transfer of smolts and other challenging aquaculture procedures, e.g., chemical delousing procedures. Here we used a suite of established cardiorespiratory indices, ones that can be reliably measured in individual fish over a period of several days, to define the general athletic robustness of a salmon. Collectively, these indices measured the fish's aerobic capacity for sustained swimming, ability to recover from exhaustion, ability to produce ATP aerobically at muscle tissue level, and ability to tolerate hypoxia and temporarily support metabolic demands with anaerobic metabolism. 
Selective breeding for rapid growth, delayed maturity and high fecundity (as well as rearing in a sheltered environment with an unlimited food source and the absence of predators) appears to have reduced athletic robustness in farmed fish. For instance, cultured salmonids characteristically have a high body condition factor, a rounded cardiac ventricle and a low plasma level of atrial natriuretic peptides (Poppe et al., 2003; Claireaux et al., 2005; Kristensen et al., 2012b). They also display a higher incidence of cardiac aberrations (e.g., a misaligned bulbus arteriosus; Mercier et al., 2000), which have been associated with reduced capacities for cardiac pumping and oxygen delivery (Poppe and Taksdal, 2000; Poppe et al., 2002, 2003; Gamperl and Farrell, 2004; Claireaux et al., 2005). Domesticated fish also have lower swimming muscle contraction capacity and lower enzymatic capacity for aerobic energy production as compared to wild fish (Anttila et al., 2008a; Anttila and Mänttäri, 2009). Poorer swimming performance associated with domestication (McDonald et al., 1998; Jonsson and Jonsson, 2006) could reflect a reduced aerobic capacity (Fry, 1971; Claireaux et al., 2005). At an extreme, the rapid growth rate of growth hormone transgenic salmonids is similarly associated with reduced aerobic capacity and hypoxia tolerance (Farrell et al., 1997; Stevens et al., 1998; Cook et al., 2000). Thus, intensive selection for beneficial traits during commercial rearing (e.g., rapid growth) appears to have negatively impacted the physiological integrity of farmed fish (McKenzie et al., 2007), with possible consequences on smolt's ability to handle the additional energy costs and osmotic stress that accompany transfer into seawater (Usher et al., 1991).

In intensive aquaculture, exercise training can benefit fish, provided the exercise regime is not too severe, i.e., plasma stress hormones are not greatly elevated, ionic/osmotic homeostasis is not disrupted and blood flow to the digestive system is not diverted to skeletal muscle (Farrell et al., 1991; Thorarensen et al., 1993; Kiessling et al., 1994; Davison, 1997; Kieffer, 2000; McKenzie et al., 2003). Indeed, aerobic training in fish is viewed by some as an integrated approach to improve animal wellbeing (Nelson, 1989), in part because training is known to enhance oxygen extraction efficiency and supply, anaerobic metabolism, the capacity to recover from exhaustion, and reduces the osmo-respiratory compromise (Kieffer, 2000; Gallaugher et al., 2001; Kieffer, 2010). Also, aerobic training can enlarge muscle fibers in swimming muscles and mitochondria in cardiac myocytes (Davison, 1997; Castro et al., 2013), and increase oxidative enzyme activities in both red and white skeletal muscles, while reducing their anaerobic enzymes 
activities (Anttila et al., 2006; Anttila et al. 2008b). Lipid utilization (McClelland et al., 2006; Anttila et al., 2010) and the capacity to deplete muscle glycogen similarly increase after aerobic training (Hochachka, 1961; Poston et al., 1969; Pearson et al., 1990, Gamperl et al., 1994; Milligan, 1996). Furthermore, aerobic training of Atlantic salmon parr before sea transfer enhanced gene expression for infectious pancreas necrosis virus resistance and seawater relevant ion-transportation pathways (Castro et al., 2011; Castro et al., 2013; Esbaugh et al., 2014). Consequently, the aquaculture industry has growing interests in identifying appropriate exercise regimes that would strengthen stress tolerance, growth and survival before and after sea transfer (Grisdale-Helland et al., 2013).

For the present study, we tested the hypothesis that exercise training of domesticated and wild strains of Atlantic salmon parr would improve their athletic robustness measured at biochemical and whole animal levels. We also reasoned that by screening swimming performance ahead of training with a constant acceleration test, superior and inferior swimmers could be segregated according to their athletic robustness (Anttila et al., 2014a). Thus, after the screening protocol, Atlantic salmon parr were given an 18-day incremental aerobic exercise training regime in a hatchery setting followed by measurements of a suite of respiratory indices to evaluate athletic robustness. We further hypothesized that the domesticated Bolaks strain should have a lower athletic robustness and less cardiorespiratory plasticity in response to exercise training than the wild Lardal strain. To ensure a broad characterization of athletic robustness, we measured each fish's standard metabolic rate (SMR, the minimal maintenance metabolic rate of an aquatic ectotherm in a post-absorptive and inactive states; Fry and Hart, 1948) and maximum rate of oxygen uptake $\left(M \square \mathrm{O}_{2 \max }\right.$, as an estimate proxy of maximum metabolic rate; Fry, 1947; Brett and Groves, 1979), as well as the absolute aerobic scope (AAS) and factorial aerobic scope (FAS), which are indices of the aerobic capacity for activities (Pörtner and Farrell, 2008; Pörtner, 2010; Clark et al., 2013). The capacity for both aerobic and anaerobic energy production in red and white swimming muscles were assessed by measuring the citrate synthase (CS) and lactate dehydrogenase (LDH) activities, respectively. Hypoxia tolerance and anaerobic capacity were characterized by measuring, respectively, the critical oxygen level $\left(\mathrm{O}_{2 \text { crit }}\right.$, the capability to extract dissolved oxygen; Ultsch et al., 1978) and the incipient lethal oxygen saturation (ILOS, the minimal oxygen saturation that aquatic animal maintaining equilibrium; Claireaux et al., 2013). 
Lastly, we measured excess post-exercise oxygen consumption (EPOC; Lee et al., 2003) to quantify the ability to recover from exhaustion.

\section{Materials and methods}

\subsection{Experimental animals and rearing conditions}

The Bolaks (domesticated) strain was generated from eggs of 7 females that were fertilized by 2 males and the fertilized eggs were incubated at $7{ }^{\circ} \mathrm{C}$ in SalmoBreed (Bergen, Norway) until 396 degree days (dd). The Lærdal (wild) strain were generated from eggs of 5 females that were fertilized by 2 males and the fertilized eggs were incubated at $7{ }^{\circ} \mathrm{C}$ on site until $410 \mathrm{dd}$. Eyed eggs were then transported to Nofima research station, Sunndalsøra, Norway and incubated in 5$6{ }^{\circ} \mathrm{C}$ freshwater until hatching using side-by-side incubators (463-487 dd for Bolaks and 513-518 dd for Lardal). Emergent fry were similarly reared under identical standard conditions and fed the same diet (Skretting, Stavanger, Norway) in side-by-side $5.3 \mathrm{~m}^{3}$ circular fiberglass tanks (approximately $25 \mathrm{~kg} \mathrm{~m}^{-3}$ stock density). Rearing temperature was progressively increased to $12{ }^{\circ} \mathrm{C}$ in accordance with Norwegian aquaculture industry standards and maintained at $12{ }^{\circ} \mathrm{C}$ throughout the experiment. At $3 \mathrm{~g}$ size (bulk weighed), fish were graded to obtain homogenous populations with respect to body mass/fork length and maintain stocking density $\left(35 \mathrm{~kg} \mathrm{~m}^{-3}\right)$. At $25 \mathrm{~g}$ size and two weeks prior to swim screening, 600 fish per strain were selected to limit the variance in body mass and fork length to $\pm 3 \mathrm{~g}$ and $\pm 1 \mathrm{~cm}$, respectively, and individually tagged with a passive integrated transponder (Jojo Automasjon ÅS, Sola, Norway). Each stock was then reared in five replicate circular tanks $\left(0.1 \mathrm{~m}^{3}, \mathrm{n}=120\right.$ per strain, $36 \mathrm{~kg} \mathrm{~m}^{-3}$ stock density) until the fish were screened for their swimming performance. Throughout, water exchange and current were set and routinely adjusted to self-clean the tanks in accordance to standard procedures and to provide a nominal water current that was slightly lower [0.2-0.3 fork lengths $\left.(F L) \mathrm{s}^{-1}\right]$ than that used later for the control fish (see section 2.2). Specific growth rates were 3.40 and 3.07 in the Bolaks and Lærdal strains, respectively, during this period. Therefore, to minimize the size dichotomy, the faster growing Bolaks strain were screened, trained and tested two months ahead (September 2014) of the Lardal strain (November 2014). The experiments were approved by the 
National Animal Research Authority, according to the 'European Convention for the Protection of Vertebrate Animals used for Experimental and other Scientific Purposes' (EST 123).

The Lardal and Bolaks strains are characteristic Norwegian wild and domesticated Atlantic salmon, respectively. The Lardal strain, from the Norwegian Lardal River $\left(61^{\circ} \mathrm{N}\right)$, was selected because of its relatively large spawning population size, genetic purity, genetic stability and a limited genetic influence from aquaculture escapees (Glover et al., 2012; Finstad et al., 2013; Glover et al., 2013; Johnsen et al., 2013). Its freshwater habitat has a large water discharge and low water temperature, which are typical conditions for wild Atlantic salmon in Norway (Brooks et al., 2006; Urke et al., 2013). The Lardal strain consists mainly of late maturing (2 and 3 seawinter) spawners and the migration route passes through the longest (>200 km) Norwegian fjord system, Sognefjorden. The domesticated Bolaks strain originates from and is primarily produced as broodstock in Western Norway. The two founding strains were from the Vosso $\left(60^{\circ} \mathrm{N}\right)$ and Årøy $\left(61^{\circ} \mathrm{N}\right)$ Rivers. For the first five generations until 2000, selective breeding with other strains focused on promoting characteristics of rapid growth and delayed sexual maturation, after which a family-based breeding program was established to enhance specific disease resistance, fillet quality and coloration as selective breeding traits in addition to growth and delayed sexual maturation.

\subsection{Screening and training protocols}

The experimental design is summarized in Fig. 1. For each strain, 480 parr were initially screened using the following protocol. Batches of 120 parr were fasted for 1 day before being transferred to a pair of side-by-side transparent PVC tunnels (60 fish per tunnel; stocking density $=29 \mathrm{~kg} \mathrm{~m}^{-3}$ ). The swimming section was $2 \mathrm{~m}$ long and $20 \mathrm{~cm}$ in diameter, which allowed 4 fish to easily swim abreast, if required. Fish were habituated for $4 \mathrm{~h}$, while maintaining station in the water current $\left(0.5 \mathrm{FL} \mathrm{s}^{-1}\right)$ without tail beats. Water velocity was incremented by $5 \mathrm{~cm} \mathrm{~s}^{-1}$ every 10 min until all the fish in a tunnel had reached exhaustion (typically $\leq 145 \mathrm{~cm} \mathrm{~s}^{-1}$ ). Fatigued fish, which were too refractory to remove themselves from the net at the rear of the swimming section, were manually removed via a hatch situated above the back grid and scanned for their pit-tags. Their body mass, fork length, final water speed $\left(U_{\max } ;\right.$ Farrell, 2008) and swimming duration 
were recorded. $U_{\max }$ for each fish was calculated from the proportion of the time period spent at the final velocity increment (Brett, 1964). Both swim tunnels received rearing tank water $\left(12 \pm 0.5^{\circ} \mathrm{C}\right.$ ) from a $7 \mathrm{~m}^{3}$ reservoir via a pump (VAKI Heathro Self Priming 6” pump, VAKI Aquaculture Systems Ltd., Kópavogur, Iceland). Water flow from each pump and to each swim tunnel was independently controlled with a Cubix remote controller (HBC-radiomatic GmbH, Crailsheim, Germany) and a Micronics Portaflow 300 ultrasonic flowmeter that monitored water flow in the swim tunnel (Micronics Ltd., Buckinghamshire, UK). The design of the apparatus was based on a Brett-type swimming respirometer, which has been extensively and critically tested since its conception over 50 years ago (Brett, 1964). We improved on Brett's original design by inserting flow straightening devices in the section situated upstream from the swimming section to ensure lamellar flow and a proper cross-sectional water velocity profile. The maximum water velocity was approximately $145 \mathrm{~cm} \mathrm{~s}^{-1}$.

For each population and test, the first $20 \%$ and last $20 \%$ of each group of 120 fish to reach fatigue were categorized as inferior and superior swimmers (Figs. 2A \& 2B). The respirometry tests (Section 2.3) and enzyme activity assays (Section 2.4) were performed only on these subgroups to maximize our chances of segregating athletic robustness. The remaining fish were returned unused to their original rearing tanks.

For the exercise-training regime, each swim tunnel contained 40 inferior and 40 superior swimmers (stock density $=38 \mathrm{~kg} \mathrm{~m}^{-3}$ ). The training lasted 18 days, followed by a 2-day recovery period (Fig. 1). One swim tunnel (water velocity of $0.5 \mathrm{FL} \mathrm{s}^{-1}$ ) was used for control fish, which would spread themselves along the length of the swim tunnel and only swim occasionally (using slow and small-amplitude tail beats to move forward). The other swim tunnel was used for aerobic exercise training, which involved maintaining the water velocity at $2 \mathrm{FL} \mathrm{s}^{-1}$ for the first 7 days, at $2.4 \mathrm{FL} \mathrm{s}^{-1}$ for next 7 days and at $2.8 \mathrm{FL} \mathrm{s}^{-1}$ for the last 4 days. Again, fish spread themselves along the length of the swim tunnel and typically maintained station in the water current with only occasional changes in location. Fish were fed a daily ration of $2 \%$ biomass through a hatch situated above honeycomb grid at the front of the swim tunnels, which was connected to an automatic belt feeder. A technician monitored feeding twice daily to ensure the pellets were evenly spread and fish were feeding. After the 18-day period, fish were segregated 
into 8 groups of 40 fish, from which up to 12 fish per group were subsequently used for the respirometry testing and 15 fish per group were used to measure enzyme activities. The rest of the fish were used for other purposes that were separate from current experiments.

\subsection{Respirometry trials}

Prior to testing, the fish groups were returned to their rearing tanks for 3 days where they were held on a 24-h photoperiod with a limited diet to prevent smoltification and further growth. The control group were tested first to allow the exercised group some recovery, a practice that would likely be needed for an industry application prior to sea transfer. Each batch of respirometry trials simultaneously examined 8 fish that had been fasted for 3 days using intermittent-flow respirometers (water volume $=2.1 \mathrm{~L}$ each) were submerged in a water reservoir $(3 \mathrm{~m} \mathrm{x} 0.5 \mathrm{~m}$ and $0.3 \mathrm{~m}$ deep), where aerated water $\left(12 \pm 0.5^{\circ} \mathrm{C}\right)$ flowed continuously. Water flow through the respirometers was regulated using computer-controlled flush pumps (Compact 600, EHEIM, Germany) and relays (AquaResp, University of Copenhagen, Helsingør, Denmark).

Continuously mixing of the respirometry chamber was assured by a circulation loop, into which an optical oxygen probe (Robust Oxygen Probe OXROB3, Pyroscience, Germany \& Oxygen Minisensor, PreSens, Germany) that continuously monitored dissolved oxygen saturation (\% sat.). Prior to every respirometry trial, the oxygen probes were calibrated to $0 \%$ sat. (water saturated with sodium sulfite) and $100 \%$ air saturation (fully aerated water).

A respirometry trial began with a chasing protocol, during which each fish was individually hand chased in a 10-L bucket for 10-min and then given a 2-min air exposure. At the end of air exposure, the fish was placed immediately in a respirometer during flushing mode. An oxygen uptake rate $\left(\dot{M}_{2}\right)$ measurement cycle consisted of flush, stabilization and measurement periods. Only oxygen saturation values obtained during the measurement periods were used to calculate $\dot{M} \mathrm{O}_{2}$. Oxygen saturation was then monitored using a measuring cycle comprised of a $30 \mathrm{~s}$ flush, a $45 \mathrm{~s}$ stabilization and a $105 \mathrm{~s}$ measurement at the first $2 \mathrm{~h}$ to capture the maximum $\dot{M} \mathrm{O}_{2}$, which was assigned $M \square \mathrm{O}_{2 \max }$. The computer recorded the first $\dot{M} \mathrm{O}_{2}$ value about $150 \mathrm{~s}$ to $180 \mathrm{~s}$ after the fish was placed in the respirometer. As $\mathrm{MO}_{2}$ decreased toward SMR, the measurement cycle was changed to a $120 \mathrm{~s}$ flush, a $80 \mathrm{~s}$ stabilization and a $400 \mathrm{~s}$ measurement to guarantee that oxygen 
saturation was $>97 \%$ at the start of the measurement period. These measurements continued for 2 or 3 days in a dark and quiet environment, allowing the fish to fully adjust to the respirometer and reach a minimal maintenance $\mathrm{MO}_{2}$ (SMR; Section 2.5).

$\mathrm{O}_{2 \text { crit }}$ and ILOS were determined at the end of a trial by introducing hypoxic water into the respirometers. Water was pumped (Compact 600, EHEIM, Germany) from the water reservoir to the top of a gas equilibration column where it trickled down through nitrogen gas that was injected into the bottom. Air-saturation of the water decreased progressively to $10 \%$ over an 8 -h period, during which the $\mathrm{M}_{2}$ measurement cycles were a 60 s flush, a $45 \mathrm{~s}$ stabilization and a $195 \mathrm{~s}$ measurement. When a fish lost its equilibrium, the air saturation was noted as the ILOS. $\mathrm{O}_{2 \text { crit }}$ was determined with a post-experiment calculation (Section 2.5). Fish were immediately resuscitated with well-aerated water at $12^{\circ} \mathrm{C}$ (survival rate was $94 \%$ ). To eliminate microbial respiration, the entire system was disinfected with Virkon S (Lilleborg Profesjonell, Oslo, Norway) for $6 \mathrm{~h}$ on completion of every respirometry trial.

\subsection{Enzyme activity assays}

Fish were weighed, measured and euthanized 5 days after the 18-day training regime. Blocks of red and white muscles were removed from the mid-line at the mid-point between the adipose fin and tail fin and frozen immediately and separately in liquid nitrogen for storage at $-80{ }^{\circ} \mathrm{C}$ until analyzed. For enzymatic analysis, each muscle sample was homogenized separately in 19 vols of homogenization buffer ( $0.1 \%$ Triton, $50 \mathrm{mM}$ Hepes, $1 \mathrm{mM}$ EDTA, pH 7.4). Citrate synthase (CS, EC 2.3.3.1) and lactate dehydrogenase (LDH, EC 1.1.1.27) activities were measured according to Dalziel et al. (2012) at $21^{\circ} \mathrm{C}$. The measurements were done with EnSpire 2300 Multilabel Reader (Perkin Elmer, Turku, Finland) and the final substrate concentrations followed the optimizations were done by Dalziel et al. (2012). For CS the concentrations were $0.15 \mathrm{mM}$ DTNB, $0.15 \mathrm{mM}$ acetyl CoA and $0.5 \mathrm{mM}$ oxalacetic acid in $50 \mathrm{mM}$ Tris (pH 8.0) and for LDH $0.27 \mathrm{mM}$ NADH and $25 \mathrm{mM}$ sodium pyruvate in $50 \mathrm{mM}$ Tris (pH 7.4). Assays were performed in triplicate for each sample and a background reaction rate was subtracted. The activities of enzymes were calculated $\mathrm{g}^{-1}$ tissue. All the reagents were purchased from Sigma-Aldrich Chemie GmbH, Steinheim, Germany. 


\subsection{Data analysis}

Only $\%$ air saturation data with a linear decrease and $\mathrm{R}^{2}>0.8$ during the measurement cycle were accepted for an accurate calculation of $\dot{M} \mathrm{O}_{2}$. SMR was determined from between 288 and 432 measurement cycles per fish. In the absence of a fully accepted method to estimate SMR (see Chabot et al., 2016), we used an R script (Chabot et al., 2016) to determine two estimates: a) a quantile of 0.2 (q0.2), and b) the mean of the lowest $10 \dot{M}_{2}$ values (Low 10) after removing the lowest $2 \%$ of the dataset. $M \square \mathrm{O}_{2 \max }$ was not always the first $\dot{M} \mathrm{O}_{2}$ measurement made after chasing and was as late as the $5^{\text {th }} \dot{M} \mathrm{O}_{2}$ measurement, but averaged the $2^{\text {nd }} \dot{M} \mathrm{O}_{2}$ measurement. AAS $=$ SMR minus $M \square \mathrm{O}_{2 \max }$, while FAS $=M \square \mathrm{O}_{2 \max } / \mathrm{SMR}$. EPOC was calculated from the integral of the area bounded by the actual $\dot{M O}_{2}$ measurement and SMR. However, we only used the recovery period until $\dot{M} \mathrm{O}_{2}$ remained at or below to $\mathrm{SMR}+10 \%$ for at least 3 measurement cycles, rather than using SMR per se. This strategy limited the obvious overestimate of EPOC and its duration due to spontaneous fish activity. We acknowledge that while our approach slightly underestimates EPOC and its duration, the effect of spontaneous activity on EPOC would be numerically much greater. Yet, even with this modification, EPOC could not be calculated reliably in 20 individuals given the extent of their spontaneous activity during the recovery period. $\mathrm{O}_{2 \text { crit }}$ was derived using $\mathrm{R}$ script from the intersection of a regression line for $\dot{M} \mathrm{O}_{2}$ versus oxygen saturation and the SMR (Claireaux and Chabot, 2016).

Statistical comparisons of SMR, $M \square \mathrm{O}_{2 \max }$, AAS, FAS, EPOC, $\mathrm{O}_{2 \text { crit, }}$ ILOS, CS and LDH activities were made using a two-way (strain \& training) multivariate analysis of variance (MANOVA) with Pillai's Trace test to correct for unbalanced sample size, followed by multiple ANOVAs and Tukey HSD post-hoc (Zar, 1996). $\log _{10}$ transformations were applied on $M \square \mathrm{O}_{2 \max }$ and EPOC in Low10 dataset to achieve the assumption of multivariate normality. Statistical comparisons of $U_{\max }$, regarding strain and initial swimming capacity, were made using a two-way ANOVA with Tukey HSD post-hoc. Statistical analyses were conducted in R (ver. 3.2.2; R Development Core Team 2015) and SigmaPlot (ver. 12.5). Statistical significance was assigned when $\alpha<0.05$. 


\section{Results}

\subsection{Swimming capacity and growth}

Prior to respirometry, body mass was $9.2 \%$ larger $(\mathrm{p}=0.002)$ in the domesticated Bolaks strain and their fork length was $2.1 \%$ longer than in the Lærdal strain ( $\mathrm{p}=0.001$ ) (Bolaks: $35.6 \pm 0.8 \mathrm{~g}$, $14.4 \pm 0.1 \mathrm{~cm}$; Lærdal: $32.6 \pm 0.5 \mathrm{~g}, 14.1 \pm 0.1 \mathrm{~cm}$ ) (Table S1). Regression analysis found no significant correlations either between respiratory indices and body mass, or between enzymatic variables and body mass within either strain or swim groupings (Figs. S1 \& S2).

The cumulative frequency polygons demonstrated that neither absolute nor relative $U_{\max }$ had normal distributions (see insets in Fig. 2) and that the distribution patterns were similar for each screening trial and for both strains (Figs. S3 \& S4). Superior swimmers swam on average almost twice as fast as inferior swimmers using absolute swimming speed (entire fish population: $117.0 \pm 1.9$ vs $65.1 \pm 0.3 \mathrm{~cm} \mathrm{~s}^{-1} ; \mathrm{p}<0.001$; only fish used for respirometry: $121.9 \pm 2.6$ vs $66.8 \pm 2.7$ $\mathrm{cm} \mathrm{s}^{-1} ; \mathrm{p}<0.001$; Fig. $2 \mathrm{~A}$ ) as well as relative swimming speed (entire fish population: $8.6 \pm 0.1 \mathrm{vs}$ $4.8 \pm 0.1 F L \mathrm{~s} \mathrm{~s}^{-1} ; \mathrm{p}<0.001$; only fish used for respirometry: $9.0 \pm 0.2$ vs $4.9 \pm 0.2 F L \mathrm{~s}^{-1} ; \mathrm{p}<0.001$; Fig. 2B). Unexpectedly, the wild Lardal strain had a significantly lower $U_{\max }$ than the domesticated Bolaks strain for both superior and inferior swimmers (Fig. 2).

\subsection{Respirometry indices (based on Low10 SMR values)}

Contrary to the initial hypothesis, screening had no main effect on the metabolic and enzymatic indices (Three-way MANOVA: $\mathrm{p}=0.7$; Table $\mathrm{S} 2$ ). Therefore, the data of superior and inferior swimmers were pooled for subsequent analyses of effects of training and strain. Training and strain (Two-way MANOVA: training $\mathrm{p}<0.001$; strain $\mathrm{p}<0.001$; Table 1), as well as the interaction (Two-way MANOVA: $\mathrm{p}=0.002$; Table 1), significantly influenced several of the metabolic and enzymatic indices.

Overall SMR ( $\mathrm{n}=90$ ) was $65.8 \pm 1.6 \mathrm{mg} \mathrm{O}_{2} \mathrm{~h}^{-1} \mathrm{~kg}^{-1}$. Neither training, nor strain had independent 
effects on SMR ( $\mathrm{p} \geq 0.19$; Table 1). Nevertheless, strain significantly influenced $M \square \mathrm{O}_{2 \max }$, with wild strain displaying a $24 \%$ higher $M \square \mathrm{O}_{2 \max }$ than domesticated strain (392.8 \pm 10.7 vs.

$317.8 \pm 7.3 \mathrm{mg} \mathrm{O}_{2} \mathrm{~h}^{-1} \mathrm{~kg}^{-1}, \mathrm{p}<0.001$, Table 2). Moreover, there was an interaction between training and strain ( $\mathrm{p}=0.036$, Table 2), with training increasing $M \square \mathrm{O}_{2 \max }$ by $16 \%$ in wild fish (p=0.045) but not in domesticated fish ( $\mathrm{p}=0.98$, Fig. 3).

Since AAS and FAS are derived from SMR and $M \square \mathrm{O}_{2 \max }$, the training and strain effects on AAS and FAS were similar to those for $M \square \mathrm{O}_{2 \max }$. Training increased AAS by $12 \%$ (306.2 \pm 12.2 vs. $272.7 \pm 7.9 \mathrm{mg} \mathrm{O}_{2} \mathrm{~h}^{-1} \mathrm{~kg}^{-1}, \mathrm{p}=0.003$, Table 1) and AAS was $30 \%$ higher for wild fish than domesticated fish (327.1 \pm 10.9 vs. $251.4 \pm 5.9 \mathrm{mg} \mathrm{O}_{2} \mathrm{~h}^{-1} \mathrm{~kg}^{-1}, \mathrm{p}<0.001$, Table 1). Wild fish had a $17 \%$ higher AAS after training $(\mathrm{p}=0.009)$, whereas AAS was unresponsive to training in domesticated fish ( $\mathrm{p}=0.96$, Fig. 3). Wild fish had a $24 \%$ higher FAS than domesticated fish (6.2 \pm 0.2 vs. $5.0 \pm 0.2, \mathrm{p}<0.001$, Table 1$)$ and training increased FAS by $7 \%$ ( $5.8 \pm 0.2$ vs. $5.4 \pm 0.2$, $\mathrm{p}=0.005$; Table 1). There was an interaction between strain and training $(\mathrm{p}=0.012)$, but neither the domesticated nor wild fish reached statistical significance for an effect of training on FAS (Fig. 3).

Training significantly increased EPOC by $30 \%$ (914.0 \pm 55.7 vs. $704.1 \pm 25.0 \mathrm{mg} \mathrm{O}_{2} \mathrm{~kg}^{-1}, \mathrm{p}=0.002$, Table 1), but strain ( $\mathrm{p}=0.92$, Table 1) had no independent main effect on EPOC. There was no interaction between training and strain $(\mathrm{p}=0.32$, Table 1$)$ and while EPOC increased significantly $(\mathrm{p}=0.02)$ by $49 \%$ as a result of training in the wild fish, there was no training effect $(\mathrm{p}=0.3)$ on EPOC in the domesticated fish (Fig. 3).

Training and strain significantly impacted $\mathrm{O}_{2 \text { crit }}$ and ILOS. Training decreased overall $\mathrm{O}_{2 \text { crit }}$ by $6 \%$ (16.2 \pm 0.4 vs. $17.2 \pm 0.3 \%$ sat., $\mathrm{p}<0.001$, Table 1$)$ and $\mathrm{O}_{2 \text { crit }}$ was $9 \%$ lower in wild fish than domesticated fish ( $15.9 \pm 0.5$ vs $17.5 \pm 0.3 \%$ sat., $\mathrm{p}=0.0028$, Table 1$)$. Training also decreased overall ILOS by $5 \%$ ( $14.6 \pm 0.5$ vs $15.3 \pm 0.4 \%$ sat., $\mathrm{p}=0.001$, Table 2$)$ and ILOS was $12 \%$ lower in wild fish than domesticated fish ( $14.0 \pm 0.5$ vs $15.9 \pm 0.3 \%$ sat., $\mathrm{p}=0.002$, Table 2$)$. Although there were interactions between strain and training for both $\mathrm{O}_{2 \text { crit }}$ and ILOS ( $\left.\mathrm{p} \leq 0.038\right)$, the training effect on $\mathrm{O}_{2 \text { crit }}$ and ILOS did not reach statistical significance for either strain (Fig. 3). 
Aerobic ATP production capacity, as measured by CS activity, was 16-times higher in red than in white swimming muscle (Fig. 4A \& 4B; see Table S3 for morphometrics), as anticipated. Training had significant effects on CS activity that were more pronounced in wild than in domesticated fish. In red muscle, training significantly increased CS activity by $22 \%$ in wild fish ( $\mathrm{p}<0.001)$ and by $11 \%$ in domesticated fish ( $\mathrm{p}<0.001$, Table 2, Fig. 4A). In white muscle, CS activity was $30 \%$ higher in wild compared with domesticated fish ( $\mathrm{p}<0.001)$, but training did not influence the CS activity of white muscle in either strain (Table 2, Fig. 4B). LDH activity, an index of anaerobic capacity, was 7-times higher in white swimming muscle than in red swimming muscle (Fig. 4C \& 4D), as expected. Training reduced LDH activity in red muscle by $35 \%$ ( $\mathrm{p}<0.001$ ) in wild fish but not in the domesticated fish (Table 2, Fig. 4C). In white muscle, LDH activity was $6 \%$ significantly lower in wild fish compared with domesticated fish $(\mathrm{p}=0.0016)$, and training significantly increased LDH activity by $8 \%(\mathrm{p}=0.048)$ in wild fish but not in domesticated fish after training (Table 2, Fig. 4D). Therefore, in terms of key metabolic enzymes, wild fish generally had higher aerobic enzyme activity levels and a higher plasticity that responded to aerobic training than domesticated fish.

\subsection{Respirometry indices (based on q0.2 SMR values)}

By definition, the q0.2 estimate of SMR will always generate numerically higher value compared with the Low 10 estimate. The q0.2 estimates (data not shown) were always $<11 \%$ numerical higher than the Low10 estimates (Table S2). Even so, the outcomes of the comparisons for training and strain main effects were no different (Table 1). For clarity, our figures only present the Low10 estimate of SMR. 


\section{Discussion}

The general goal of this work was to examine if generations of selective breeding for growth (on average a 14\% enhancement per generation for the first six generations; Gjedrem and Baranski, 2009) have influenced the athletic robustness and cardiorespiratory plasticity of domesticated Bolaks Atlantic salmon strain. This goal was pursued using a suite of indices for respiratory performance and hypoxia tolerance, along with measurements of muscle enzymatic activities that collectively characterized aerobic and anaerobic capacities and which we collectively term athletic robustness. Plasticity in response to aerobic exercise training was examined and the comparison between the domesticated Bolaks strain and the Norwegian Lardal wild strain provided additional insights into the effects of domestication. Lastly, by experimentally separating each strain into inferior and superior swimmers, we hoped to establish an association between athletic robustness and swim performance during a simple screening test. The most important potential of this work for aquaculture is the insight into how selective breeding for growth has produced negative and possibly unforeseen effects on athletic robustness and cardiorespiratory plasticity. The domesticated strain certainly had a reduced athletic robustness and also less plasticity in response to a short exercise-training regime compared with a wild strain. Further, the potential of domesticated fish benefiting from exercise training was not completely lost but remained below that for the wild strain, providing further insight into the trade off the athletic robustness resulting from commercial aquaculture practices when compared with cardiorespiratory performance of a wild strain. Thus, the potential of using exercise protocols to train fish to reduce seawater transfer mortality in aquaculture and providing physiological basis for selective breeding to regain athletic robustness and cardiorespiratory plasticity warrant further investigation.

\subsection{Training effects}

The potential benefits of exercise training in fish are well established (Davison, 1997; Kieffer, 2010). Therefore, we anticipated that an 18-day regime would be sufficiently long and intense enough to improve athletic robustness (defined generally here as a high aerobic capacity, rapid recovery from exhaustion and superior hypoxia tolerance). This proved to be true for the wild 
Lardal strain to a much greater extent than for the domesticated Bolaks strain. Training induced increases in $M \square \mathrm{O}_{2 \max }$, AAS, EPOC, CS activity in red muscle and LDH activity in white muscle in the wild Lardal strain, effects that were absent in the domesticated Bolaks strain. Training only enhanced CS activity in red muscle in the Bolaks strain.

These observations support our hypothesis that the domesticated Bolaks strain had less cardiorespiratory plasticity than the wild Lardal strain in response to exercise training. This important discovery means that commercial aquaculture practices might need to adopt a longer duration of training than used here to sufficiently exploit the full plasticity of the cardiorespiratory system in domesticated strains (Davison, 1997; Gamperl and Farrell, 2004), because previous long-term, but less intensive (1-1.5 $\left.F L \mathrm{~s} \mathrm{~s}^{-1}\right)$ exercise regimes have induced training effects, i.e., improved growth, greater ventricle mass and enhanced disease resistance in both domesticated and wild Atlantic salmon (Castro et al., 2011; Castro et al., 2013; GrisdaleHelland et al., 2013; Anttila et al., 2014a). It is also possible that our trained fish underwent some detraining prior to the start of the respirometry measurements and potentially the domesticated strain may have detrained faster. A recovery period post-training is inevitable given the need to properly measure the respirometry indices and the industry requirement for transferring smolts to seawater. The diverse training effects observed for the wild strain after 17 days clearly illustrates the retention of training effects despite this recovery period, as well as the practical potential for the aquaculture industry. Indeed, previous studies report retention of training effects well beyond 17 days. For example, following a 48-day aerobic training regime (up to $1.0 F L \mathrm{~s} \mathrm{~s}^{-1}$ ), 119 days were needed before juvenile Atlantic salmon lost the growth benefit and 48 days to lose the gene expression for the acquired resistance to infectious pancreas necrosis virus (Castro et al., 2011). Coho salmon smolts exercised for 40 days (at $1.5 F L ~ s^{-1}$ ) retained enhanced swimming endurance for 60 days (Besner and Smith, 1983), while striped bass fry exercised for 60 days (at either 1.5-2.4 FL s ${ }^{-1}$ or 2.4-3.6 FL s${ }^{-1}$ ) retained enhanced swimming performance for 56 days (Young and Cech, 1993). Nevertheless, the current training regime was shorter than previous studies, which might lead to faster detraining. The relatively short training duration used here was aimed to discover a minimum training period (and associated economic cost) to enhance physiological robustness. Atlantic salmon aquaculture may benefit from water velocities in the range of 1-2 FL s ${ }^{-1}$ and a longer training duration than used here. Of course, once suitable 
protocols are established for training intensity, duration and timing for different life-stages, the ultimate goal is to measure marine survival of trained smolts during commercial grow out. Alternatively, a different genetic selection program may be needed to prevent the trade off of cardiorespiratory robustness.

Exercise training enhanced anaerobic glycolytic capacity (LDH activity) and utilization in white muscle of wild strain, an effect not reflected in either $\mathrm{O}_{2 \text { crit }}$ or ILOS of these two strains. Instead, it was reflected in EPOC, which is an index of a) the rapid recharging oxygen storage on hemoglobin and myoglobin ( 20\% of total; Burnett et al., 2014), b) the rapid resynthesis of creatine phosphate and adenosine triphosphate, and c) the slower lactate clearance and glycogen resynthesis (Gaesser and Brooks, 1984; Scarabello et al., 1991; Wood, 199) and possibly restoring ionic imbalances due to the osmo-respiratory compromise (Gallaugher et al., 2001). A higher CS activity in red skeletal muscle of trained fish, as observed previously (Davison, 1997; Kieffer, 2000; Gallaugher et al., 2001; Anttila et al., 2006; Anttila et al., 2008a, b), would not only aid aerobic ATP production for swimming, but would benefit aerobic ATP production during recovery. A higher LDH activity in white skeletal muscle could enhance lactate clearance (Milligan et al., 2000), something of less important in red skeletal muscle, as indicated by a reduction of LDH activity in trained wild fish here and previously (Anttila et al., 2006; Anttila et al. 2008b).

\subsection{Strain differences}

The present comparison between a domesticated strain and a wild strain was intended to provide insight into the effects of domestication. Indeed, we found support for our hypothesis that the domesticated Bolaks strain would have less cardiorespiratory plasticity and a lower athletic robustness than the wild Laerdal strain. However, precisely separating out the effect of domestication (i.e., genetic selection for growth, plentiful food, lack of predators, habituation to aquaria and people, limited environmental extremes etc.) by simply comparing a wild and a domesticated strain is impossible, especially given the mixed stock origins of the Bolaks strain following ten generations selective breeding for growth. Also, the genetic divergence between the two strains remains undetermined, even if single-nucleotide polymorphism analysis shows a 
0.30-0.32 genetic dissimilarity when compared with themselves and only a $0.31-0.38$ genetic dissimilarity when compared against each other (Nick Robinson, pers. comm.). Thus, the differences in performance between strains observed here could be due to: a) genetic selection of desirable traits, such as a faster growth rate for the Bolaks strain, b) selective pressures encountered only by the wild fish, c) random genetic drift (possibly exacerbated by population bottlenecks), or d) pre-existing genetic differences between the Lardal strain and the base populations that founded the Bolaks strain. We propose that the observed differences between Bolaks and Lardal strains are a combination of strain and domestication since the two strains of experimental fish were grown from eyed eggs in the identical hatchery conditions, and that northern and southern strains of European wild juvenile Atlantic salmon had an almost indistinguishable cardiac physiological response to warming after common garden rearing from eggs (Anttila et al., 2014b).

Support for domestication reducing the aerobic capacity of Bolaks strain comes from the lower $M \square \mathrm{O}_{2 \max }$, AAS, FAS and CS activity in white muscle when compared with the wild strain. Importantly, enhancement of AAS and FAS in the wild strain was solely through $M \square \mathrm{O}_{2 \max }$ with no change in SMR. Superior cardiorespiratory and muscular capacity of wild fish is likely the result of natural selection and adaptation to habitat, as observed in sockeye salmon (Oncorhynchus nerka; Eliason et al., 2011;) and tropical killifishes (Aphyosemion sp.; McKenzie et al., 2013). Conversely, compared with wild or semi-wild hybrid strains, domesticated fish can have up to 9-times lower aerobic enzyme activities in their swimming muscle (Anttila et al., 2008a; Anttila and Mänttäri, 2009), a lower swimming speed (McDonald et al., 1998; Reinbold et al., 2009) and a 25-84\% lower holding velocity than wild yearlings (Rimmer et al., 1985), but a higher lipid concentration in swimming muscles (McDonald et al., 1998). Underpinning the differences in swimming capacity might be the cardiac malformations common to domesticated fish (Poppe and Taksdal, 2000; Mercier et al., 2001; Poppe et al., 2003; McKenzie et al., 2007; Kristensen et al., 2012b), but hearts were not examined here simply because it is unlikely that a routine aquaculture practice prior to smolt transfer will be cardiac sampling.

\subsection{Segregation of superior and inferior swimmers with an exercise screening protocol}


Despite good evidence that a more robust cardiorespiratory system positively correlates with a superior swimming capacity in salmonids (e.g., Keen and Farrell, 1994; Claireaux et al., 2005; Farrell, 2007; McKenzie et al., 2007), we found no support for our hypothesis that superior swimmers (top $20 \%$ of each strain and despite an almost 2-fold difference in their $U_{\max }$ compared with bottom $20 \%$ of each strain) benefitted from a higher aerobic capacity at the biochemical and whole animal levels, a more rapid recovery from exhaustion and a better hypoxia tolerance. Even a exploratory three-way MANOVA model restricted to just the fastest $10 \%$ swimmers $(140 \leq$ $\left.U_{\max } \leq 145 \mathrm{~cm} \mathrm{~s}^{-1}\right)$ and slowest $10 \%$ swimmers $\left(60 \leq U_{\max } \leq 67.5 \mathrm{~cm} \mathrm{~s}^{-1}\right)$ yielded no significant differences for any respiratory index. Previous screening protocols for Atlantic salmon smolts have similarly failed to segregate inferior and superior swimmers according to their routine metabolic rate, $M \square \mathrm{O}_{2 \max }$ and aerobic scope, despite a $55 \%$ difference in their swimming capacity (Anttila et al., 2014a). Theoretically, fish cannot swim faster or longer without a metabolic cost, unless swimming is mechanically more efficient, a possibility not tested here. Interestingly, the numerical difference in EPOC between top and bottom $10 \%$ of both strains almost reached statistical significance (898.5 \pm 63.8 vs. $729.8 \pm 57.4 \mathrm{mg} \mathrm{O}_{2} \mathrm{~kg}^{-1}$, ANOVA: $\left.\mathrm{F}=3.9, \mathrm{p}=0.06\right)$, without any interaction between strain and swimming capacity. Therefore, perhaps the constant acceleration screening protocol used here does a better job of distinguishing anaerobic rather than aerobic capacity by segregating aerobic swimmers and burst-and-coast swimmers, two swimming phenotypes previously observed in wild European sea bass (Dicentrarchus labrax) (Marras et al., 2010). Fish use different gaits (burst and sprint) and muscle groups (glycolytic white skeletal muscle) to swim faster and this is why a prolonged swimming test uses incremental water velocities lasting >10 min (Jones, 1982; Rome, 1992; Hammer, 1995; Burgetz et al., 1998; Martínez et al., 2003). Our screening protocol was adapted from constant acceleration test to measure $U_{\max }$, which is approximately $33 \%$ higher than the prolonged swimming speed (Farrell, 2008). Swimming behaviours and willingness to swim also play a role in determining $U_{\max }$ (Anttila et al., 2014a), and these factors could help explain the observed results. For example, weaker swimmers in a group of 60 fish in a 2-m long swimming tunnel could position themselves behind better swimmers to use slipstream and reduce the energetics of swimming (Bell and Terhune, 1970; Anttila et al., 2014a) and therefore mask differences in cardiorespiratory indices for the truly superior swimmers. Future studies could focus, therefore, on alternative screening protocols that do a better job of assessing aerobic performance and using 
a commercial scale screening apparatus that can accommodate larger numbers of fish. With regard to the former, transitions in swimming gait (Peake and Farrell, 2004, 2005 \& 2006) could be used to highlight different swimming modes.

\subsection{SMR estimation method}

SMR is at the foundation of many of the indices reported in the current dataset (AAS, FAS, EPOC and $\mathrm{O}_{2 \text { crit }}$ all depend on SMR). According to the definition of SMR, which is the metabolism that supports basic homeostasis without any input into locomotion, digestion, growth and reproduction, SMR should locate at the left side of the distribution curve for a range of $\dot{M} \mathrm{O}_{2}$ values measured over several days in quiescent, post-absorptive fish (Steffensen et al., 1989; Steffensen et al., 1994, Chabot et al., 2016). However, effectively isolating true SMR values from active $M \square \mathrm{O}_{2}$ due to minor locomotory activity is not a trivial task. Therefore, to be objective, we provided two estimates of SMR (q0.2 and the Low10) and their derivatives (Table 1). The Low10 estimate will always be lower than the q0.2 estimate of SMR because it averages the lowest 10 values (here we also eliminated the lowest $2 \%$ of $\dot{M} \mathrm{O}_{2}$ measurements as a compensation for any measurement errors that would underestimate SMR). Given the size of the $\dot{M} \mathrm{O}_{2}$ data set used here, these lowest 10 values would approximate a $\mathrm{q} 0.12$.

In conclusion, this study demonstrated that cultivation of Atlantic salmon has likely compromised athletic robustness and plasticity. The wild Lardal strain had a significantly higher $M \square \mathrm{O}_{2 \max }$, AAS, FAS and CS activity in white muscle when compared with domesticated Bolaks strain. The wild Laerdal strain showed plasticity in response to aerobic exercise training through improvements to $M \square \mathrm{O}_{2 \max }$, AAS, EPOC and CS activity in red muscle, as well as LDH activity in white muscle, whereas training only improved CS activity in red muscle of domesticated Bolaks strain. These results suggest that the salmon breeding companies should further investigate the implications of their strong focus on growth performance because it appears to have negative consequences on athletic robustness.

\section{Acknowledgments}

The study was financed by the National Research Council of Norway and The Fishery and Aquaculture Industry Research Fund (grant no. 225219/E40). YZ was supported by Elizabeth R. 
Howland Fellowship. KA was supported by Kone Foundation. APF holds a Canada Research Chair. To Dr. Denis Chabot for providing R script for the analysis of SMR and $\mathrm{O}_{2 \text { crit. }}$ To Matthew Gilbert for critical comments.

\section{References}

Anttila, K., Mänttäri, S., Järvilehto, M., 2006. Effects of different training protocols on $\mathrm{Ca}^{2+}$ handling and oxidative capacity in skeletal muscle of Atlantic salmon (Salmo salar L.). The Journal of Experimental Biology 209, 2971-2978.

Anttila, K., Järvilehto, M., Mänttäri, S., 2008a. $\mathrm{Ca}^{2+}$ handling and oxidative capacity are greatly impaired in swimming muscles of hatchery-reared versus wild Atlantic salmon (Salmo salar). Canadian Journal of Fisheries and Aquatic Sciences 65, 10-16.

Anttila, K., Järvilehto, M., Mänttäri, S., 2008b. The swimming performance of brown trout and whitefish: the effects of exercise on $\mathrm{Ca}^{2+}$ handling and oxidative capacity of swimming muscles. J Comp Physiol 178B: 465-475

Anttila, K., Mänttäri, S., 2009. Ultrastructural differences and histochemical characteristics in swimming muscles between wild and reared Atlantic salmon. Acta Physiol 196: 249-257

Anttila, K., Jäntti, M., Mänttäri, S., 2010. Effects of training on lipid metabolism in swimming muscles of sea trout (Salmo trutta). Journal of Comparative Physiology. B, Biochemical, Systemic, and Environmental Physiology 180, 707-714.

Anttila, K., JÃ sgensen, S. M., Casselman, M. T., Timmerhaus, G., Farrell, A. P., Takle, H., 2014a. Association between swimming performance, cardiorespiratory morphometry, and thermal tolerance in Atlantic salmon (Salmo salar L.). Frontiers in Marine Science 1, 1-10.

Anttila, K., Couturier, C. S., Øverli, Ø., Johnsen, A., Marthinsen, G., Nilsson, G. E., Farrell, A. P. 2014b. Atlantic salmon show capability for cardiac acclimation to warm temperatures. Nat. Commun. 5, 4252.

Aunsmo, A., Bruheim, T., Sandberg, M., Skjerve, E., Romstad, S., Larssen, R.B., 2008. Methods for investgating patterns of mortality and quantifying cause-specific mortality and quantifying cause-specific mortality in sea-farmed Atlantic salmon Salmo salar. Disease of Aquatic Organisms 81, 99-107.

Bell, W.M., Terhune, L.D.B. 1970. Water tunnel design for fisheries research. Tech. Rep. Fish. Res. Bd. Can. 195, 1-69.

Besner, M., Smith.L.S., 1983. Modification of swimming mode and stamina in two stocks of coho salmon (Oncorhynchus kisutch) by differing levels of Iong-term continuous exercise. Can. J. Fish. Aquat. Sci. 40, 933-939. 
Brett, J., 1964. The respiratory metabolism and swimming performance of young sockeye salmon. Journal of the Fisheries Board of Canada 5.

Brett, J. R., Groves, T. D. D. 1979. Physiological energetics. vol. VIII. In: Hoar, W.S., Randall, D. J., and Brett, J. R. (Eds), Fish Physiology. Academic Press, New York, pp. 279-352.

Brooks, R. J., Nielsen, P. S., Saltveit, S. J., 2006. Effecg of stream regulation on population parameters of atlantic salmon (Salmo salar L.) in the river Lærdalselva, western Norway. Regulated Rivers: Research and Management 4, 347-354.

Burgetz, I. J., Rojas-Vargas, A., Hinch, S. G., Randall, D. J., 1998. Initial recruitment of anaerobic metabolism during sub-maximal swimming in rainbow trout (Oncorhynchus mykiss). J. Exp. Biol. 201, 2711-2721.

Burnett, N. J., Hinch, S. G., Braun, D. C., Casselman, M. T., Middleton, C. T., Wilson, S. M., Cooke, S. J. 2014. Burst Swimming in Areas of High Flow: Delayed Consequences of Anaerobiosis in Wild Adult Sockeye Salmon. Physiological and Biochemical Zoology, 000-000.

Castro, V., Grisdale-Helland, B., Helland, S. J., Kristensen, T., Jørgensen, S. M., Helgerud, J., Claireaux, G., Farrell, A. P., Takle, H., 2011. Aerobic training stimulates growth and promotes disease resistance in Atlantic salmon (Salmo salar). Comparative Biochemistry and Physiology. Part A, Molecular and Integrative Physiology 160, 278-90.

Castro, V., Grisdale-Helland, B., Helland, S. J., Torgersen, J., Kristensen, T., Claireaux, G., Farrell, A. P., Takle, H., 2013. Cardiac molecular-acclimation mechanisms in response to swimming-induced exercise in Atlantic salmon. PloS One, 8, e55056.

Chabot, D., Farrell, A. P., Steffensen, J. F., 2016. The determination of the standard metabolic rate in fishes. Journal of Fish Biology 88, 81-121.

Claireaux, G., McKenzie, D. J., Genge, A. G., Chatelier, A., Aubin, J., Farrell, A. P., 2005. Linking swimming performance, cardiac pumping ability and cardiac anatomy in rainbow trout. The Journal of Experimental Biology 208, 1775-1784.

Claireaux, G., Théron, M., Prineau, M., Dussauze, M., Merlin, F.-X., Le Floch, S., 2013. Effects of oil exposure and dispersant use upon environmental adaptation performance and fitness in the European sea bass, Dicentrarchus labrax. Aquatic Toxicology (Amsterdam, Netherlands) 130-131, 160-170.

Claireaux, G., Chabot, D. 2016. Responses by fishes to environmental hypoxia: integration through Fry's concept of aerobic metabolic scope. Journal of Fish Biology 88, 232-251.

Clark, T. D., Sandblom, E., Jutfelt, F., 2013. Aerobic scope measurements of fishes in an era of climate change: respirometry, relevance and recommendations. The Journal of Experimental Biology 216, 2771-2782. 
Cook, J.T., McNiven, M.A., Sutterlin, A.M., 2000. Metabolic rate of pre-smelt growth-enhanced transgenic Atlantic salmon (Salmo salar). Aquaculture 188, 33-45.

Dalziel, A. C., Ou, M., Schulte, P.M., 2012. Mechanisms underlying parallel reductions in aerobic capacity in non-migratory threespine stickleback (Gasterosteus aculeatus) populations. J. Exp. Biol. 215, 746-759.

Davison, W., 1997. The effects of exercise training on teleost fish, a review of recent literature. Comparative Biochemistry and Physiology 117, 67-75.

Eliason, E. J., Clark, T. D., Hague, M. J., Hanson, L. M., Gallagher, Z. S. Jeffries, K. M., Gale, M. K., Patterson, D. A., Hinch, S. G., Farrell, A. P. 2011. Differences in thermal tolerance among sockeye salmon populations. Science 2496, 109-112.

Esbaugh, A. J., Kristensen, T., Takle, H., and Grosell, M. 2014. The effects of sustained aerobic swimming on osmoregulatory pathways in Atlantic salmon Salmo salar smolts. Journal of Fish Biology 8, 1355-1368.

Farrell, A. P., Johansen, J. A., and Suarez, R. K. 1991. Effects of exercise-training on cardiac performance and muscle enzymes in rainbow trout, Oncorhynchus mykiss. Fish Physiology and Biochemistry 9, 303-312.

Farrell, A. P., Bennett, W., and Devlin, R. H., 1997. Growth-enhanced transgenic salmon can be inferior swimmers. Canadian Journal of Zoology 75, 335-337.

Farrell, A. P. 2007. Cardiorespiratory performance during prolonged swimming tests with salmonids: a perspective on temperature effects and potential analytical pitfalls. Philosophical Transactions of the Royal Society of London. Series B, Biological Sciences 362, 2017-2030.

Farrell, A. P. 2008. Comparisons of swimming performance in rainbow trout using constant acceleration and critical swimming speed tests. Journal of Fish Biology, 72, 693-710.

Finstad, A. G., Sættem, L. M., and Einum, S., 2013. Historical abundance and spatial distributions of spawners determine juvenile habitat accessibility in salmon: implications for population dynamics and management targets. NRC Research Press 70, 1339-1345.

Fry, F. E. J., 1947. Effects of the environment on animal activity. Publications of the Ontario Fisheries Research Laboratory 68, 1-63.

Fry, F. E. J., Hart, J. S., 1948. The relation of temperature to oxygen consumption in the goldfish. Biol. Bull. 94, 66-77.

Fry, F. E. J., 1971. The effect of environmental factors on the physiology of fish. In Fish Physiology, vol. 6 (ed. W. S. Hoar and D. J. Randall). New York: Academic Press, pp. 1-98.

Gamperl, A.K., Vijayan, M.M., Boutilier, R.G., 1994. Experimental control of stress hormone 
levels in fishes: techniques and applications. Rev. Fish Biol. Fish. 4, 215-225.

Gamperl, A. K., Farrell, A. P., 2004. Cardiac plasticity in fishes: environmental influences and intraspecific differences. The Journal of Experimental Biology, 207, 2539-2550.

Gaesser, G. A. Brooks, G. A., 1984. Metabolic bases of excess post- exercise oxygen consumption: a review. Med. Sci. Sports Exer. 16, 29-43.

Gallaugher, P. E., Thorarensen, H., Kiessling, A., Farrell, A. P., 2001. Effects of high intensity exercise training on cardiovascular function, oxygen uptake, internal oxygen transport and osmotic balance in Chinook salmon (Oncorhynchus tshawytscha) during critical speed swimming. J. Exp. Biol. 204, 2861-2872.

Gjedrem, T., Baranski, M., 2009. Selective Breeding in Aquaculture: An Introduction. vol. X. In: T. Gjedrem and M. Baranski (Eds) Reviews: Methods and Technologies in Fish Biology and Fisheries. Springer, New York, pp. 13-23

Glover, K. A., Quintela, M., Wennevik, V., Besnier, F., Sørvik, A. G. E., Skaala, Ø., 2012. Three decades of farmed escapees in the wild: A spatio-temporal analysis of Atlantic salmon population genetic structure throughout Norway. PLOS ONE 8, 1-18.

Glover, K. A., Pertoldi, C., Besnier, F., Wennevik, V., Kent, M., Skaala, Ø. 2013., Atlantic salmon populations invaded by farmed escapees: quantifying genetic introgression with a Bayesian approach and SNPs. BMC Genetics 14, 74-93.

Grisdale-Helland, B., Takle, H., Helland, S. J., 2013. Aerobic exercise increases the utilization efficiency of energy and protein for growth in Atlantic salmon post-smolts. Aquaculture 406-407, 43-51.

Hammer, C., 1995. Fatigue and exercise tests with fish. Comparative Biochemistry and Physiology - A Physiology 112, 1-20.

Hochachka, P.W., 1961. The effect of physical training on oxygen debt and glycogen reserves in trout. Can. J. Zool. 39, 767-776.

Iversen, M., Finstad, B., McKinley, R.S., Eliassen, R.A., Carlsen, K.T., Evjen, T. 2005. Stress responses in Atlantic salmon (Salmo salar L.) smolts during commercial well boat transports, and effects on survival after transfer to sea. Aquaculture 243, 373-382.

Johnsen, A., Brabrand, Å, Anmarkrud, J. A., Bjørnstad, G. Pavels, H., Saltveit, S. J. 2013. Impact of human-induced environmental changes on genetic structure and variability in Atlantic salmon, Salmo salar. Fisheries Management and Ecology 21, 32-41.

Jones D. R., 1982. Anaerobic exercise in teleost fish. Can. J. Zool. 60, 1131-1134. 
Jørgensen, E., Jobling, M., 1994. Feeding and growth of exercised and unexercised juvenile Atlantic salmon in freshwater, and performance after transfer to seawater. Aquaculture International 164, 154-164.

Jonsson, B., Jonsson, N., 2006 Cultured Atlantic salmon in nature: a review of their ecology and interaction with wild fish. Journal of Marine Science 63, 1162-1181.

Keen, J., Farrell, A., 1994. Prolonged swimming speed and maximum cardiac performance of rainbow trout, Oncorhynchus mykiss, acclimated to two different water temperatures. Comparative Biochemistry and Physiology 108, 287-295.

Kieffer, J. D., 2000. Limits to exhaustive exercise in fish. Comparative Biochemistry and Physiology Part A 126, 161-179.

Kieffer, J. D., 2010. Perspective - Exercise in fish: 50 + years and going strong. Comparative Biochemistry and Physiology Part A 156, 163-168.

Kiessling, A., Gallaugher, P., Thorarensen, H., Kolok, A., Eales, J. G., Sweeting, R., Gong, B., Dosanjh, B., Farrell, A. P. and Higgs, D., 1994. Influence of sustained exercise and endurance training on growth, muscle physiology, cardiovascular parameters, and plasma levels of metabolic hormones of seawater adapted all-female chinook salmon. In: MacKinlay, D. (Eds.) High Performance Fish, Proc. First Fish Biology Congress, Am. Fish. Soc., Vancouver. pp. 300-305.

Kristensen, T., Åtland, Å., Rosten, T., Urke, H.A., Rosseland, B.O., 2009. Important influentwater quality parameters at freshwater production sites in two salmon producing countries. Aquaculture Engineering 41, 53-59.

Kristensen, T., Haugen, T.O., Rosten, T., Fjellheim, A., Åtland, Å., Rosseland, B.O., 2012a. Effects of production intensity and production strategies in commercial Atlantic salmon smolt (Salmo salar L.) production on subsequent performance in early sea stage. Fish Physiol. Biochem. 38, 273-282.

Kristensen, T., Urke, H.A., Poppe, T.T., Takle, H., 2012b. Atrial natriuretic peptide levels and heart morphology in migrating Atlantic salmon (Salmo salar) smolts from 4 rivers with different environmental conditions. Aquaculture 362, 172-176.

Lee, C., Devlin, R., Farrell, A., 2003. Swimming performance, oxygen consumption and excess post- exercise oxygen consumption in adult transgenic and ocean- ranched coho salmon. Journal of Fish Biology 62, 753-766.

Martínez, M., Guderley, H., Dutil, J.-D., Winger, P. D., He, P., Walsh, S. J., 2003. Condition, prolonged swimming performance and muscle metabolic capacities of cod Gadus morhua. The Journal of Experimental Biology 206, 503-511. 
Marras, S., Claireaux, G., McKenzie, D.J., and Nelson, J.A., 2010. Individual variation and repeatability in aerobic and anaerobic swimming performance of European sea bass, Dicentrarchus Labrax. The Journal of Experimental Biology 213, 26-31.

Maxime, V., Soulier, P., Quentel, C., Aldrin, J.F., Peyraud, C., 1986. Comparative study of oxygen consumption and blood parameters in rainbow trout (Salmo gairdneri R.) and brown trout (Salmo trutta L.), both in fresh water and seawater during summer increase of water temperature. Ichtyophysiologica Acta 10,185-200.

Maxime, V., Peyraud-Waitzenegger, M., Claireaux, G., Peyraud, C., 1990. Effects of rapid transfer from sea water to fresh water on respiratory variables, blood acid-base status and $\mathrm{O}_{2}$ affinity of haemoglobin in Atlantic salmon (Salmo salar L.). Journal of Comparative Physiology B, 160, 31-39.

McClelland, G.B., Craig, P.M., Dhekney, K., Dipardo, S., 2006. Temperature- and exerciseinduced gene expression and metabolic enzyme changes in skeletal muscle of adult zebrafish (Danio rerio). J Physiol 577, 739-751.

McCormick, S.D., Saunders, R.L., 1987. Preparatory physiological adaptations for marine life of salmonids: osmoregulation. growth and metabolism. Am. Fish. Sot. Symp. 1, 211-229.

McDonald, D.G., Milligan, C.L., McFarlane, W.J., Croke, S., Currie, S., Hooke, B., Angus, R.B., Tufts, B.L., Davidson, K., 1998. Condition and performance of juvenile Atlantic salmon (Salmo salar): effects of rearing practices on hatchery fish and comparison with wild fish. Can. J. Fish. Aquat. Sci. 55, 1208-1219.

McKenzie, D. J., Shingles, A., Taylor, E. B. 2003. Sub-lethal plasma ammonia accumulation and the exercise performance of salmonids. Comparative Biochemistry and Physiology A135, $515-526$.

McKenzie, D. J., Pedersen, P. B., Jokumsen, A., 2007. Aspects of respiratory physiology and energetics in rainbow trout (Oncorhynchus mykiss) families with different size-at-age and condition factor. Aquaculture 263, 280-294.

McKenzie, D. J., Estivales, G., Svendsen, J. C., Steffensen, J. F. Agnèse, J.F., 2013. Local adaptation to altitude underlies divergent thermal physiology in tropical killifishes of the genus Aphyosemion. PLoS ONE 8, e54345.

Mercier, C., Aubin, J., Lefrançois, C., Claireaux, G., 2001. Cardiac disorders in farmed adult brown trout (Salmo trutta). J. Fish Dis. 60, 117-137.

Milligan, C.L., 1996. Metabolic recovery from exhaustive exercise in rainbow trout. Comp. Biochem. Physiol. 113A, 51-60.

Milligan, C.L., Hooke, G.B., Johnson, C., 2000. Sustained swimming at low velocity following a bout of exhaustive exercise enhances metabolic recovery in rainbow trout. Journal of Experimental Biology 203, 921-926. 
Neill, W.H., Miller, J.M., Van Der Veer, H.W., Winemiller, K.O., 1994. Ecophysiology of marine fish recruitment: a conceptual framework for understanding interannual variability. Neth. J. Sea Res. 32, 135-152.

Nelson, J.A., 1989. Critical swimming speeds of yellow perch Perca flaTescens : comparison of populations from a naturally acidic lake and a circumneutral lake in acid and neutral water. J. Exp. Biol. 145, 239-254.

Peake, S.J., A.P. Farrell. 2004. Locomotory behaviour and post-exercise physiology in relation to swimming speed, gait transition and metabolism in free-swimming smallmouth bass (Micropterus dolomieu). J. Exp. Biol. 207: 1563-1575.

Peake, S.J., A.P. Farrell. 2005. Postexercise physiology and repeat performance behaviour of free-swimming smallmouth bass in an experimental raceway. Physiol. Biochem. Zool. 78: 801-807.

Peake, S.J., A.P. Farrell. 2006. Fatigue is a behavioural response in respirometer-confined smallmouth bass. J. Fish Biol. 68: 1742-1755.

Pearson, M.P., Spriet, L.L., Stevens, E.D., 1990. Effect of spring training on swim performance and white muscle metabolism during exercise and recovery in rainbow trout (Salmo gairdneri ). J. Exp. Biol. 149, 45-60.

Poppe, T.T., Taksdal, T., 2000. Ventricular hypoplasia in farmed Atlantic salmon Salmo salar. Dis. Aquat. Org. 42, 35-40.

Poppe, T.T., Johansen, R., Tørud, B., 2002. Cardiac abnormality with associated hernia in farmed rainbow trout Oncorhynchus mykiss. Dis. Aquat. Org. 50, 153-155.

Poppe, T.T., Johansen, R., Gunnes, G., Tørud, B., 2003. Heart morphology in wild and farmed Atlantic salmon Salmo salar and rainbow trout Oncorhynchus mykiss. Dis. Aquat. Org. 57, 103-108.

Pörtner, H. O., Farrell, A. P., 2008. Physiology and climate change. Science 322, 690-692.

Pörtner, H. O. 2010. Oxygen- and capacity-limitation of thermal tolerance: a matrix for integrating climate-related stressor effects in marine ecosystems. J. Exp. Biol. 213, 881-893.

Poston, H.A., McCartney, T.H., Pyle, E.A., 1969. The effect of physical conditioning upon the growth, stamina, and carbohydrate metabolism of brook trout. Fish. Res. Bull. 31 (36), 2531.

Randall, D. J., Brauner, C. J., 1991. Effects of environmental factors on exercise in fish. Journal of Experimental Biology 160, 113-126.

R Development Core Team. 2015. R: a language and environ- ment for statistical computing. R Foundation for Statistical Computing, Vienna. http://www.R-project.org/. 
Reinbold, D., Thorgaard, G. H., Carter, P. A., 2009. Reduced swimming performance and increased growth in domesticated rainbow trout, Oncorhynchus mykiss. Canadian Journal of Fisheries and Aquatic Sciences 66, 1025-1032.

Rimmer, D. M., Saunders, R. L., Paim, U., 1985. Effects of temperature and season on the position holding performance of juvenile Atlantic salmon (Salmo salar). Canadian Journal of Zoology 63, 92-96.

Rome, L. C., 1992. Scaling of muscle fibres and locomotion. J. Exp. Biol. 168, 243-252.

Sardella, B. A. Brauner, C. J., 2007. The osmo-respiratory compromise in fish: the effects of physiological state and the environment. In: Fernandes, M.N., Rantin, F.T., and Glass, M.L. (Eds), Fish Respiration and Environment. Science publishers, New Hampshire. pp. 147-165.

Scarabello, M., 1991. Glycogen depletion in juvenile rainbow trout as an experimental test of the oxygen debt hypothesis. Canadian Journal of Zoology 69, 2562-2568.

Stevens, E.D., Sutterlin, A., Cook, T., 1998. Respiratory metabolism and swimming performance in growth hormone transgenic Atlantic salmon. Can. J. Fish. Aquat. Sci. 55, 2028-2035.

Steffensen, J. F. 1989. Some errors in respirometry of aquatic breathers: how to avoid and correct for them. Fish Physiology and Biochemistry 6, 49-59.

Steffensen, J. F., Bushnell, P. G., Schurmann, H., 1994. Oxygen consumption in four species of teleosts from Greenland: no evidence of metabolic cold adaptation. Polar Biology 14, 49-54.

Thorarensen, H., Gallaugher, P. E., Kiessling, A. K., Farrell, A. P. 1993. Intestinal blood flow in swimming Chinook salmon (Oncorhynchus tshawytscha) and the effects. Journal of Experimental Biology 179, 115-129.

Ultsch, G. R., Boschung, H., Ross, M. J. 1978. Metabolism, critical oxygen tension, and habitat selection in darters (Etheostoma). Ecology 59, 99-107.

Urke, H. A., Kristense, T., Ulvund, J. B., Alfredsen, J. A. 2013. Riverine and fjord migration of wild and hatchery-reared Atlantic salmon smolts. Fisheries management and Ecology 20, 544-552.

Usher, M.L., Talbot. C., Eddy, F.B., 1991. Effects of transfer to seawater on growth and feeding in Atlantic salmon smolts (Salmo salar L.). Aquaculture 94, 309-326.

Van Leeuwen, T.E., Rosenfeld, J.S., Richards, J.G., 2011. Effects of food ration on SMR: influence of food consumption on individual variation in metabolic rate in juvenile coho salmon (Onchorhynchus kisutch). The Journal of Animal Ecology 81, 395-402.

Wood, C. M., 1991. Acid-Base and Ion Balance, metabolism, and their interactions, after exhaustive exercise in fish. J. Exp. Biol. 160, 285-308. 
Young, P. S., Cech Jr. J. J., 1993. Effects of exercise conditioning on stress responses and recovery in cultured and wild young-of-the-year striped bass, Morone saxatilis. Canadian Journal of Fisheries and Aquatic Sciences 50, 2094-2099.

Zar J.H. 1996. Biostatistical Analysis 3rd ed. Prentice-Hall, New Jersey, pp. 718. 


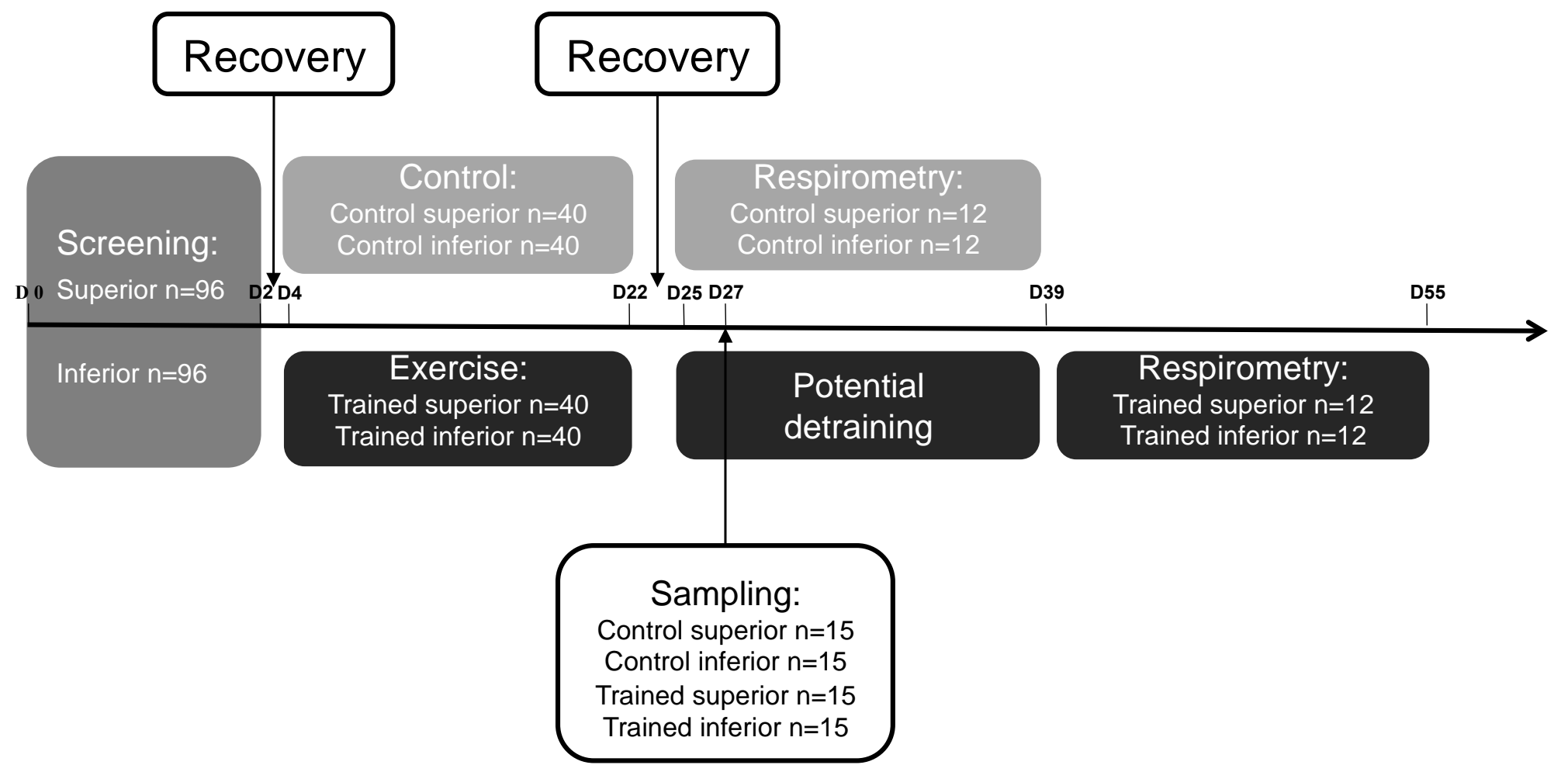

Fig. 1. Experimental design and timeline of screening, training, tissue sampling for enzyme activity assays, and respirometry conducted on Laerdal (wild) and Bolaks (domesticated) Atlantic salmon (Salmo salar) parr. An identical experimental design was practiced on the two strains. 


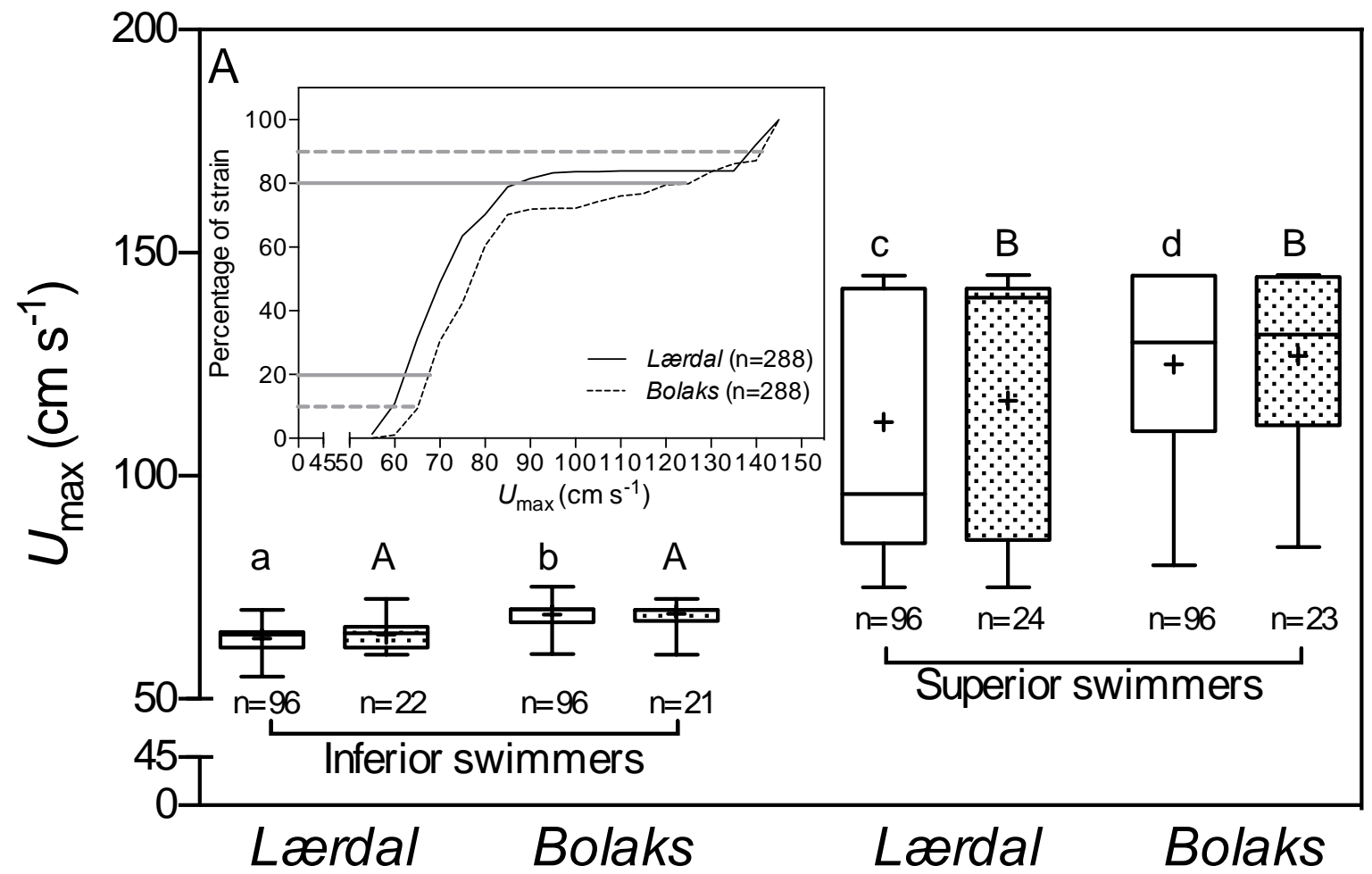




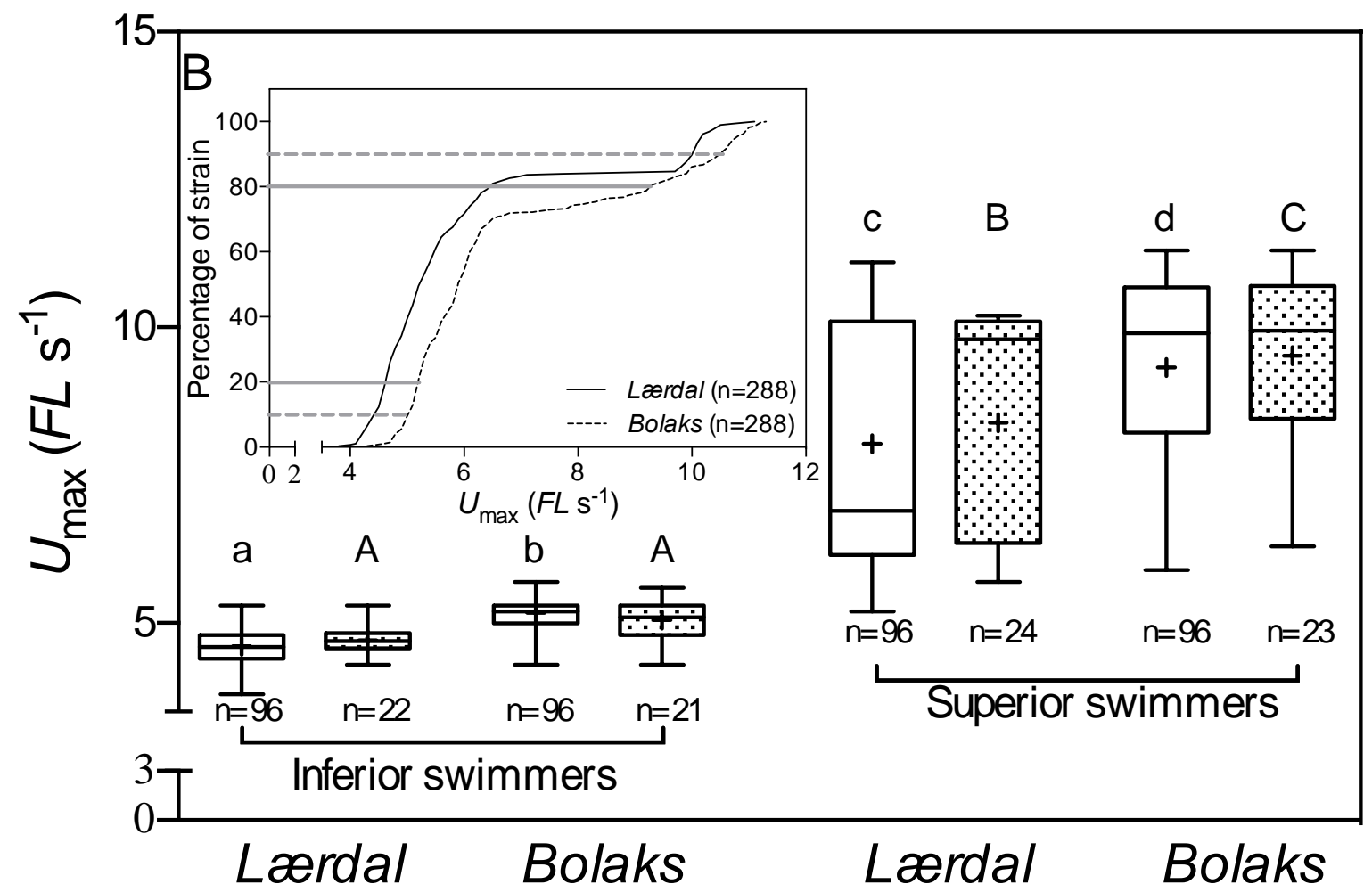

Fig. 2. A) Absolute and B) relative maximum swimming capacity $\left(U_{\max }\right)$ of inferior and superior swimmers of the Lardal (wild) and Bolaks (domesticated) Atlantic salmon (Salmo salar) parr. The results for the screening test $(n=96)$ and the sub-sample used for respirometry $(n=21-24)$ are presented separately. Each boxplot shows the interquartile range and $95 \%$ coefficient variation with the mean is shown as ' + '. Different lowercase letters indicate significant differences $(P<0.05)$ in screening test and different uppercase letters indicate significant differences in the fish sampled by respirometry, detected by two-way ANOVA Tukey HSD post-hoc. There were no significant differences $(P>0.05)$ between fish tested by screening protocol and the fish sampled by respirometry in respective swimming groups, tested by Student's t-test. The insets show the cumulative frequency polygons for $U_{\max }$ of both strains. The inferior or superior $10 \%$ and $20 \%$ of swimmers are indicated as horizontal dash and solid lines respectively. 

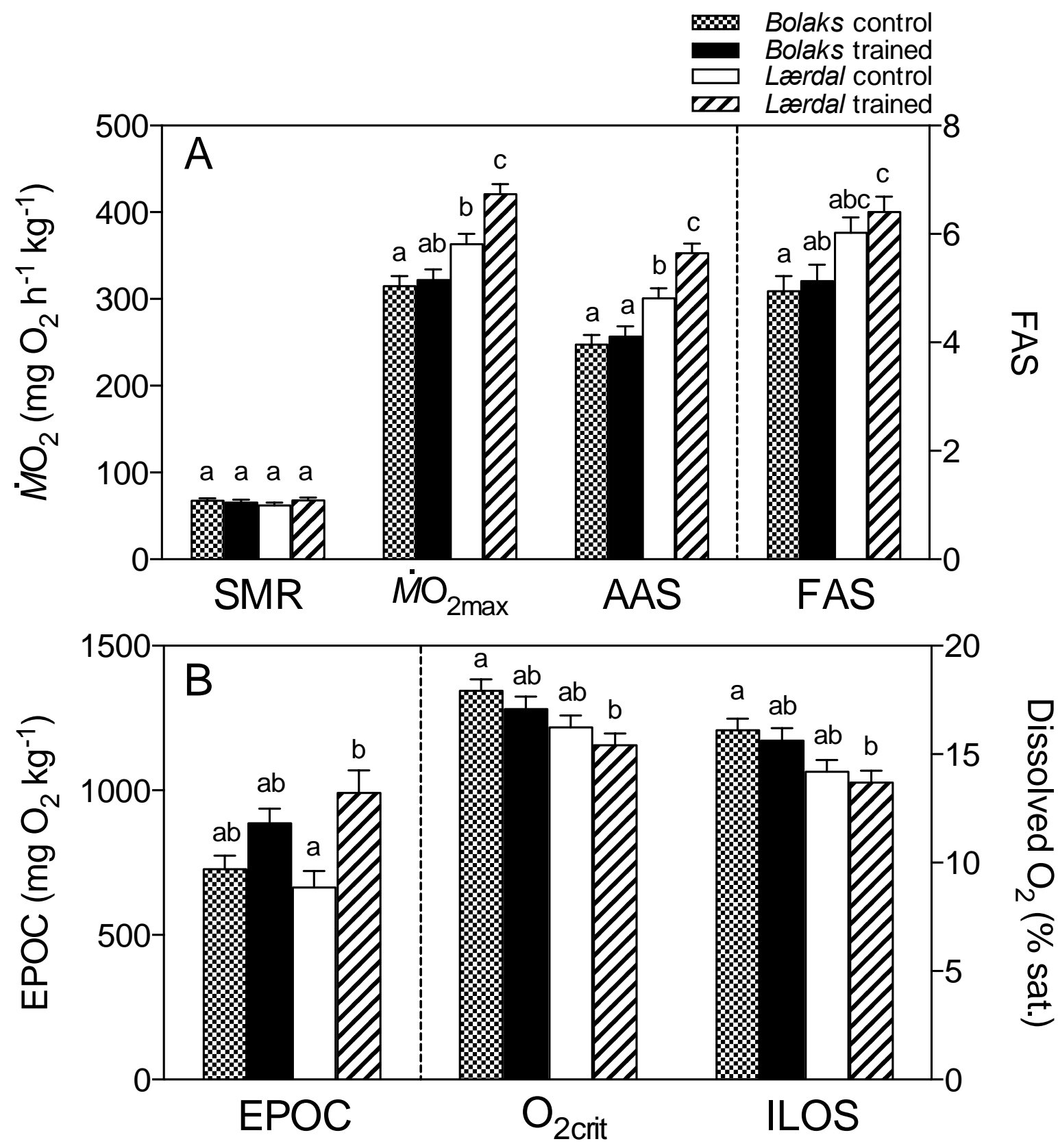

Fig. 3. Interactive effects of domestication and exercise training on A) standard metabolic rate (SMR), maximal metabolic rate (MMR), absolute aerobic scope (AAS) and factorial aerobic scope (FAS); B) excess post-exercise oxygen consumption (EPOC), critical oxygen level $\left(\mathrm{O}_{2 \text { crit }}\right)$ and incipient lethal oxygen saturation (ILOS) of Atlantic salmon (Salmo salar) parr. Different letters indicate significant differences between groups within a respiratory index $(P<0.05)$ by two-way ANOVAs and Tukey HSD post-hoc. Values are mean \pm s.e.m., $\mathrm{n}=24$ in Bolaks untrained, 21 in Bolaks trained, 23 in Lardal untrained, 22 in Lardal trained. 
A

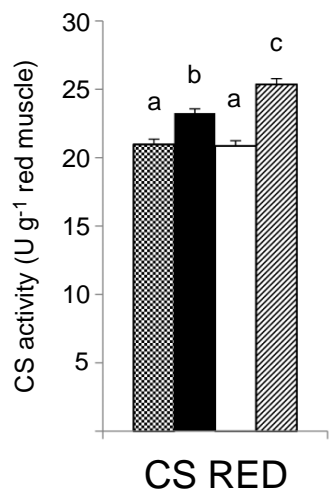

B

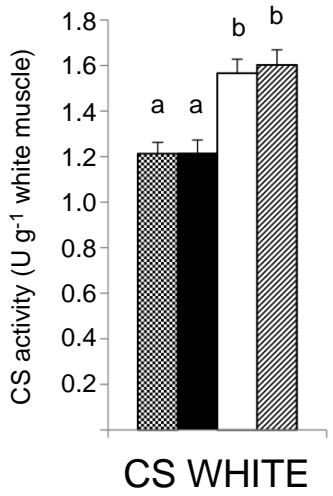

C

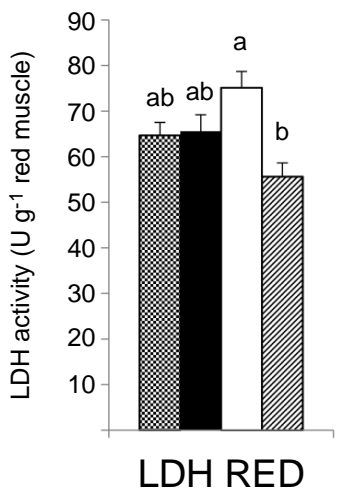

D Bolaks control

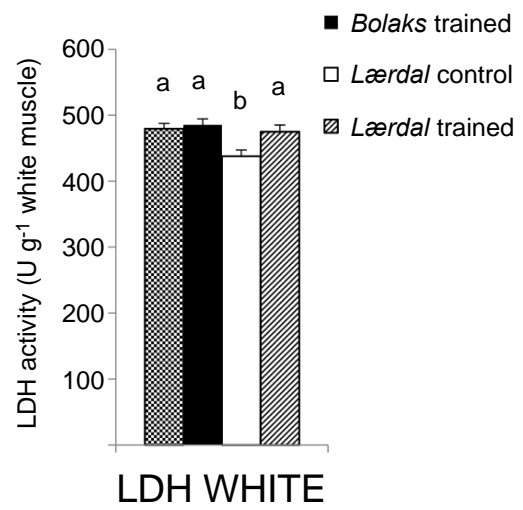

Fig. 4. The activity of A) citrate synthase (CS) in red muscle; B) CS in white muscle; C) lactate dehydrogenase (LDH) in red muscle and; and D) LDH in white muscle of Atlantic salmon (Salmo salar) parr. Different letters indicate significant differences $(P<0.05)$ between groups within muscle types (twoway ANOVAs and Tukey HSD post-hoc). Values are means \pm s.e.m., $\mathrm{n}=15$ per group. 
Table 1. A summary of the main factor effects and significant interactions (F-values and P-values) of strain and training on respiratory variables of Atlantic salmon (Salmo salar). Standard metabolic rate (SMR) was calculated using two different SMR methods (Low10 and q0.2). Absolute aerobic scope (AAS), factorial aerobic scope (FAS), excess post-exercise oxygen consumption (EPOC) and critical oxygen level $\left(\mathrm{O}_{2 \text { crit }}\right)$ also had two values corresponding with the two SMR calculation methods.

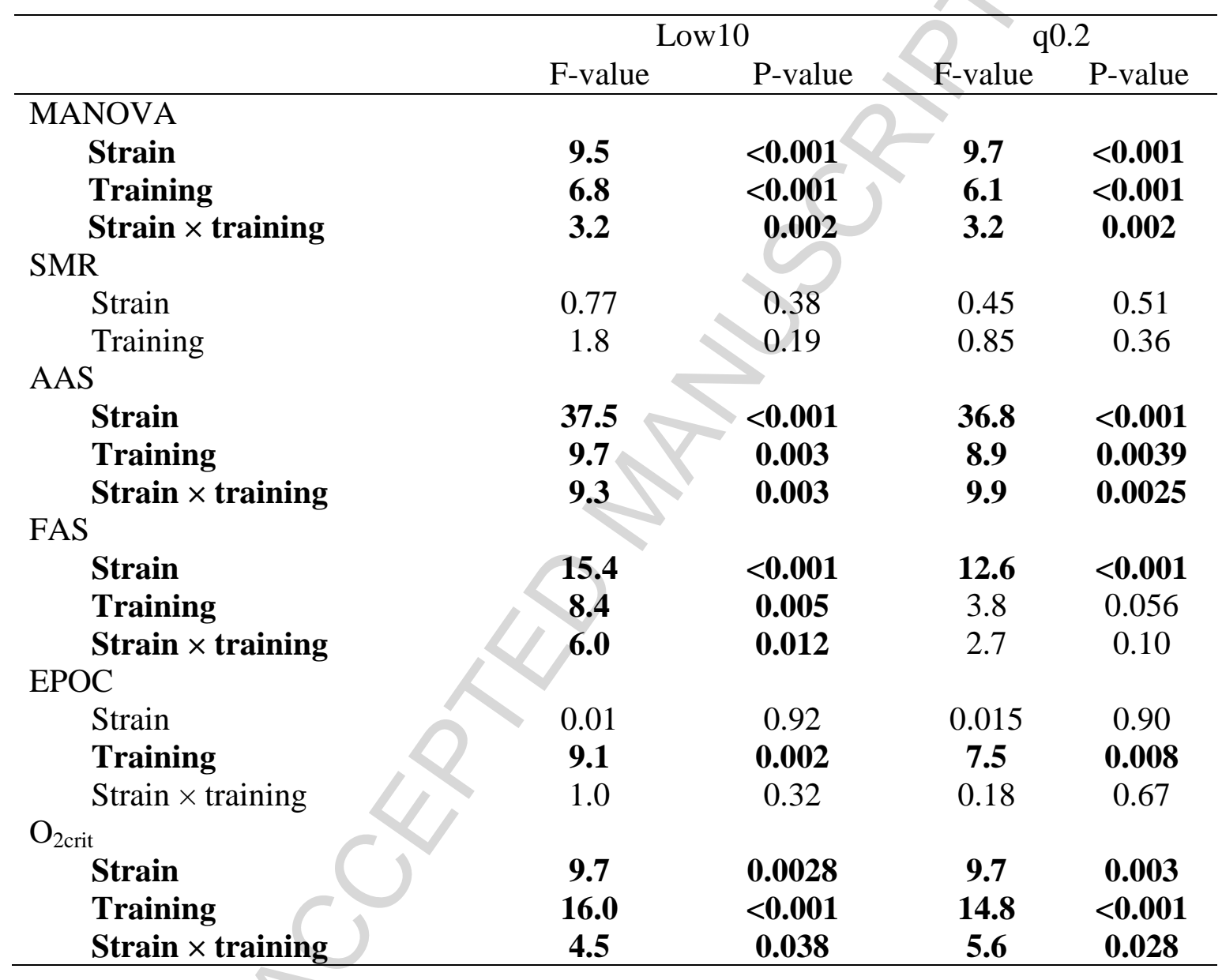


Table 2. A summary of the main factor effects and significant interactions (F-values and P-values) of strain and training on aerobic and anaerobic capacities of Atlantic salmon, illustrated by maximum rate of oxygen uptake ( $M \square \mathrm{O}_{2 \max }$ ), lethal oxygen saturation (ILOS), citrate synthase (CS) and lactate dehydrogenase (LDH) in red and white muscles.

\begin{tabular}{|c|c|c|}
\hline Factor & F-value & P-value \\
\hline \multicolumn{3}{|l|}{$M \square \mathrm{O}_{2 \max }$} \\
\hline Strain & 19.1 & $<0.001$ \\
\hline Training & 2.7 & 0.1 \\
\hline Strain $\times$ training & 4.6 & 0.036 \\
\hline \multicolumn{3}{|l|}{ ILOS } \\
\hline Strain & 10.8 & 0.002 \\
\hline Training & 11.2 & 0.001 \\
\hline Strain $\times$ training & 5.4 & 0.024 \\
\hline \multicolumn{3}{|l|}{$\mathrm{CS}$ red muscle } \\
\hline Strain & 0.23 & 0.64 \\
\hline Training & 31.7 & $<0.001$ \\
\hline Strain $\times$ Training & 8.4 & 0.005 \\
\hline \multicolumn{3}{|l|}{ CS white muscle } \\
\hline Strain & 17.8 & $<0.001$ \\
\hline Training & 1.2 & 0.29 \\
\hline \multicolumn{3}{|l|}{ LDH red muscle } \\
\hline Strain & 0.83 & 0.36 \\
\hline Training & 3.3 & 0.073 \\
\hline Strain $\times$ Training & 5.3 & 0.025 \\
\hline \multicolumn{3}{|l|}{ LDH white muscle } \\
\hline Strain & 10.9 & 0.0016 \\
\hline Training & 1.6 & 0.22 \\
\hline
\end{tabular}

